\title{
Ciência da Linguagem: uma reflexão sobre o conceito de paradigmas
}

\section{RESUMO}

Paula Regina Scoz Domingos Damázio

prsddamazio@gmail.com

Universidade Federal do Paraná (UFPR), Curitiba, Paraná, Brasil.

Roberta Pires de Oliveira

ropiolive@gmail.com

Universidade Federal do Paraná (UFPR), Curitiba, Paraná, Brasil.

\begin{abstract}
Neste artigo, discutimos criticamente a proposta epistemológica de Pires de Oliveira e Basso (2011). Os autores propõem que a linguística contemporânea se estrutura em dois paradigmas: o científico e o humanista. O objetivo é questionar a aplicação do conceito de paradigma para o caso da linguística. Argumentaremos que ele é inadequado para descrever a linguística atual. Vamos propor a noção de comunidades de fala para explicar o momento atual da linguística. Com isso, espera-se motivar novos estudos na necessária discussão em epistemologia da linguística, especialmente no que se refere à aplicação do modelo kuhniano.
\end{abstract}

PALAVRAS-CHAVE: Paradigma científico. Paradigma humanista. Epistemologia da Linguística. Comunidade de fala. 


\section{INTRODUÇÃO}

Passados quase um século, desde sua fundação, a linguística inegavelmente sofreu várias modificações. Do estruturalismo ao gerativismo e às várias abordagens funcionais, são muitas as frentes que hoje atuam nessa ciência, refletindo com isso o intenso debate e a vivacidade da área.

Essa pluralidade de abordagens coloca inevitavelmente uma reflexão no que podemos denominar de epistemologia das teorias linguísticas: estaria a linguística em um momento pré-paradigmático, como entende Kuhn (1982), faz sentido falarmos em paradigma para a linguística? Como caracterizá-la?

Neste artigo, discutimos a proposta de Pires de Oliveira e Basso (2011) que apresenta um quadro geral das teorias linguísticas atuais levando em conta o método adotado pelas teorias na construção do conhecimento. Os autores propõem que é possível entender o quadro atual da linguística a partir de dois paradigmas: o humanista e o científico. Apesar de bastante esquemática, a proposta motiva uma série de questões, sendo uma delas a própria adequação do conceito de paradigma para o caso da linguística. Abordaremos essa questão neste artigo.

Na primeira seção, discutimos, brevemente, a questão do objeto teórico da linguística. Pode parecer simples equacionar a linguística ao estudo científico da linguagem humana, como fazem boa parte dos manuais introdutórios à linguística, porém olhando mais de perto se percebe a pluralidade de teorias decorrentes das mais diversas perspectivas sobre o que é a linguagem humana. Seria essa pluralidade uma evidência de "incomensurabilidade"? Nesse sentido, a proposta paradigmática que divide os estudos linguísticos em dois modelos gerais, o científico e o humanista, coloca a mesma questão, desta vez para os paradigmas: seriam eles incomunicáveis? Este é o tema da primeira seção deste artigo.

$\mathrm{Na}$ segunda seção, discutimos mais profundamente o que seriam os paradigmas na linguística, quais suas características e o que delimita cada forma de reflexão. O critério utilizado por Pires de Oliveira e Basso (2011) foi observar a metodologia adotada pelas teorias linguísticas. Constatam que alguns estudos utilizam uma metodologia científica em suas investigações, como é o caso dos estudos formalistas e funcionalistas. Por outro lado, há estudos que utilizam uma metodologia mais próxima às ciências humanas, de caráter qualitativo. Baseandose na escolha metodológica teríamos então dois paradigmas, o científico e o humanista.

$\mathrm{Na}$ última seção tecemos nossas críticas quanto ao uso do conceito de paradigma aplicado à linguística argumentando que essa teoria epistemológica não é a mais adequada para refletirmos sobre a ciência da linguagem. Importante frisar que o presente artigo critica o uso do conceito de paradigma tendo em vista que ao se usar esse conceito, mesmo que de uma maneira frouxa como fazem Pires de Oliveira e Basso (2011), trazemos para o centro de debate uma certa maneira de descrever a ciência que nos parece inadequada e por isso motiva uma reflexão mais aprofundada. Não é apenas o caso de questionarmos se de fato estamos em uma fase paradigmática na linguística ou se vivemos ainda um estado préparadigmático, mas se faz sentido utilizar a proposta epistemológica de Kuhn para a linguística em específico. 
O principal argumento contra é que para podermos aplicar o conceito de paradigmas precisamos admitir que houve um momento de ciência normal e também apontar momentos de revolução científica. Na nossa compreensão, é possível argumentar que, embora haja muitos consensos na linguística contemporânea - nenhuma abordagem nega que haja fonemas, para dar um exemplo-, nunca houve um período de ciência normal em que há consenso sobre os problemas a serem ainda resolvidos; o conceito de revolução científica já foi aplicado para explicar a contribuição de Chomsky para a linguística, mas, como iremos argumentar, essa não parece ser a melhor explicação para sua inegável contribuição. ${ }^{1}$ Se é assim, então não parece muito adequada a utilização do termo paradigma para denominar os supostamente dois principais modelos de reflexão dentro da ciência da linguagem, conforme proposta por Pires de Oliveira e Basso (2011).

Ao fim do artigo, apontamos uma teoria epistemológica que, no nosso entender, pode ser uma proposta mais adequada para a reflexão em filosofia da linguística. O conceito de comunidades de fala, atribuído à epistemologia de Ludwik Fleck (1979), aparenta apreender com mais acuidade o que observamos nessa ciência.

\section{O OBJETO TEÓRICO DA LINGUÍSTICA}

Há uma longa tradição na descrição das ciências, em particular depois da década de 1970, que tende a entender que o objeto de estudos de qualquer ciência e, portanto, da linguística em particular, não pode ser delimitado previamente ao quadro teórico, isto é, a ideia de que as teorias debruçam-se sobre objetos observacionais - dentro do grande objeto complexo chamado linguagem humana - e a construção de cada objeto teórico está atrelada a definições próprias das teorias e das relações observadas nos fenômenos em questão a partir da visada teórica. Não se trata de afirmar que o observador interfere no que está sendo observado, mas que o objeto teórico só existe enquanto descrito por um observador em particular e que cada pesquisador tem a sua própria perspectiva.

Essa maneira de ver as abordagens da linguística aparece em Borges Neto e Dascal (1991) para quem as ciências, assim como as outras formas de saber, fazem reduções parciais da realidade (mundo das aparências), ou seja, todas elas fazem um recorte na diversidade observacional que será único. Os autores partem do princípio de que "( $\mathrm{t}$ )oda teoria delimita uma certa "região" da realidade como seu objeto de estudos" (BORGES NETO, DASCAL, 1991, p. 18). Por exemplo, uma teoria sobre a luz irá tratar apenas de fenômenos luminosos, deixando de lado qualquer outro tipo de fenômeno, como os sons ou o movimento dos corpos.

Seria esse o caso também da linguística. A região da realidade que é privilegiada pela linguística (i.e., a linguagem humana), e que constitui um conjunto de fenômenos observáveis, é o que podemos chamar, em sentido amplo, de seu objeto observacional. A partir da delimitação do objeto observacional, cada teoria irá propor diferentes entidades básicas, atribuindo propriedades aos fenômenos pertencentes ao seu campo de estudos, e estabelecendo relações entre eles. Dessa forma, transforma-se o objeto observacional em objeto teórico (BORGES NETO, DASCAL, 1991). Conforme os autores, "teorias diferentes podem construir objetos teóricos distintos sobre um mesmo objeto observacional que é 
supostamente o mesmo, bastando para isso reconhecer entidades básicas, predicados e relações diferentes no objeto observacional." (BORGES NETO, DASCAL, 1991, p. 20). Nesse sentido, as teorias, linguísticas ou não, são incomensuráveis, porque só chegamos ao objeto observacional via a linguagem de uma teoria em particular e os termos de uma teoria não se traduzem em uma outra teoria.

Se há uma certa razão para afirmarmos que os domínios do conhecimento não estão naturalmente delimitados - ao ouvirmos a cadeia de sons que constituem uma língua não há distinção clara entre os domínios da fonética e da fonologia, ou seja, é a partir do olhar humano que são criados as diferentes partições de um objeto, - essas partições tampouco são aleatórias: as propriedades que definem a sintaxe, não são as mesmas que definem a semântica, independentemente do recorte que se faça dessas disciplinas. Sabemos, na linguística contemporânea, que as ondas cerebrais nomeadas N400 refletem questões de sintaxe. Assim, o objeto teórico é sem dúvida um modo particular, e em certa medida único, de reconstruir teoricamente o objeto observacional, através do reconhecimento de entidades básicas, predicados e relações diferentes, mas, ao mesmo tempo, esse modo particular está em conversa com outros modos que se não compartilham as entidades, predicados, relações, estão submetidos a dureza da realidade, por assim dizer. A existência de uma relação neurológica entre processamento sintático e a ativação de certas ondas deve ser explicada por quaisquer das teorias. Mas essa não é a perspectiva de Borges Neto e Dascal (1991), para eles o "mesmo" objeto observacional, como uma sentença qualquer da língua, gera objetos teóricos tão extremamente distintos que a conversa entre as teorias é impossível ${ }^{2}$. Eis um exemplo dos autores:

O indivíduo A dirige-se ao indivíduo B e pronuncia as seguintes palavras: "João não viu o menino que trouxe o pacote." (BORGES NETO, DASCAL, 1991, p. 20).

Sendo (1) uma descrição de um fenômeno pertencente ao objeto observacional da linguística, é possível observar o que algumas teorias "selecionam" deste fenômeno e quais propriedades atribuem a ele. A Gramática Gerativa, por exemplo, "ignora o contexto concreto em que o enunciado (o conjunto das palavras) ocorreu e concentra-se apenas nele." (BORGES NETO, DASCAL, 1991, p. 20). Nesse momento do modelo, o enunciado é visto como uma estrutura superficial, à qual se associam estruturas mais abstratas (Estrutura-P, Estrutura-S e Forma Lógica) (cf. Chomsky, 1957). A estrutura superficial é apenas "uma manifestação sem importância teórica de um aspecto mais importante mais central - da linguagem: a gramática inscrita na mente dos falantes." (BORGES NETO, DASCAL, 1991, p. 20).

Já Austin, por exemplo, colocaria a discussão a respeito de (1) em outros termos. "Para ele, A realiza um ato de fala assertivo com o qual pretende que $B$ tome conhecimento do conteúdo proposicional do enunciado." (BORGES NETO, DASCAL, 1991, p. 20).

Se é possível identificar pontos de controvérsia, o fato de que os gerativistas privilegiam a sintaxe e os pragmaticistas o proferimento, isso não significa que não seja possível compatibilizar essas formas de descrever o objeto. Abordagens mais contemporâneas, inclusive na sintaxe gerativa, procuram integrar a sintaxe à pragmática ${ }^{3}$. 
Para Borges Neto e Dascal (1991), temos uma teoria que se concentra em identificar a estrutura do enunciado em termos de estrutura superficial, outra pode abordar o objeto em termos de atos de fala, e assim por diante. Dessa forma,

(s)e ignorarmos momentaneamente as eventuais diferenças de extensão dos objetos observacionais, e considerarmos que todas as teorias linguísticas delimitam o mesmo objeto observacional, encontraremos as razões da diversidade teórica nas divergências metodológicas e ontológicas que certamente ocorrerão quando da passagem do objeto observacional para o objeto teórico. (BORGES NETO, 1996, p. 21, grifo do autor).

O modo particular como cada teoria olha para a diversidade de fenômenos observáveis gera um modo particular de lidar com esses fenômenos criando, assim, objetos teóricos distintos, daí resultando a diversidade epistemológica da linguística. Essa maneira de enxergar uma ciência como a linguística já está profetizada na fala fundacional de Saussure, que propõe, no Curso de Linguística Geral, a distinção de dois objetos para a linguística:

O estudo da linguagem comporta, portanto, duas partes: uma, essencial, tem por objeto a língua, que é social em sua essência e independente do indivíduo; esse estudo é unicamente psíquico; outra, secundária, tem por objeto a parte individual da linguagem, vale dizer, a fala, inclusive a fonação que é psico-física. (SAUSSURE, 1995, p. 28).

Para Saussure, "cumpre escolher entre dois caminhos impossíveis de trilhar ao mesmo tempo; devem ser seguidos separadamente." (SAUSSURE, 1995, p. 28). É também de Saussure a famosa colocação de que o ponto de vista cria o objeto. Parece, pois, que essa linha tem tradição nos estudos linguísticos; trata-se talvez de uma maneira de naturalizar a ideia de que a escolha pelo tipo de investigação dependerá em última instância do próprio ponto de vista do linguista. Parece ser assim uma necessidade adotar uma única maneira de ver o objeto:

é necessário, pois, privilegiar um enfoque, ignorando - ao menos temporariamente - todos os outros. Assim, se por alguma razão, uma abordagem sociologizante da linguagem me parece mais interessante e frutífera, fatalmente deixarei de lado abordagens logicizantes ou psicologizantes. E isso se dará em todos os casos. (BORGES NETO, 1996, p. 5).

Assim, é necessário que cada abordagem encontre relações diferentes para um mesmo objeto observacional, construindo objetos teóricos distintos. Ao linguista caberia escolher a via que mais atenda às suas necessidades e questões teóricas, isto é, se irá preferir ir por uma via mais sociológica, psicológica, ou lógica da linguagem etc. Para cada uma dessas vias a própria definição de linguística poderá divergir.

Mas se observarmos com algum cuidado o que efetivamente ocorre na linguística, o panorama pode ser outro. Como já procuramos pontuar ao longo da nossa breve exposição da proposta de Borges Neto e Dascal, há mais consenso do que propriamente discordância. Nenhum linguista nega que há fonema, que há proferimentos, que há sintaxe e semântica. Funcionalistas, formalistas ou analistas do discurso concordam que há um componente inato para as línguas. $\mathrm{O}$ peso que cada um dá a esse componente, como cada um entende que esse componente se deu, é controverso porque ainda não sabemos como isso ocorreu. Além disso, há mais de um exemplo de abordagens miscigenadas, por assim dizer, que seriam absolutamente impossíveis se vivêssemos efetivamente em uma situação de 
intradutibilidade entre as teorias, como querem aqueles autores. Talvez o caso mais conhecido na linguística brasileira seja a chamada sociolinguística paramétrica que faz tanto uma abordagem sintática quanto sócio-histórica do fenômeno de mudança linguística ${ }^{4}$. Na linguística, como ela é efetivamente praticada, há muito mais intercâmbio, mais conversas do que o panorama das diferenças intransponíveis deixa entrever.

Um caso muito ilustrativo é a questão do foco, cuja pesquisa iniciou com o funcionalismo, nos escritos de Halliday, e passou para o gerativismo e para outras abordagens hoje em dia ditas conversacionais que estão para além da distinção entre função e forma; elas trabalham forma e função paralelamente. Novamente, estamos diante de miscigenações. Se os objetos fossem absolutamente incomensuráveis esses encontros seriam impossíveis. Há, é claro, várias razões para afirmar que cada teoria constrói o seu próprio nicho, mas não é assim que a ciência da linguagem parece funcionar. Parece que estamos muito mais próximos de como Fleck (1979) descreve o desenvolvimento do conceito de sífilis; várias linhas de pensamento que se manifestam em comunidades de fala se entrecruzam, numa conversa intensa. Em sua obra mais conhecida, The Genesis and Development of a Scientific Fact, Fleck (1979), analisa a história da sífilis ao longo dos séculos. A história dessa doença venérea evidencia o caráter histórico e a dependência cultural da ciência ao estilo de pensamento predominante em cada época. Até chegarmos à concepção atual, o conceito de sífilis encontrou diversas explicações para seu surgimento, - de explicações místico-éticas aos tratamentos com mercúrio iniciados no século XVIII. O exemplo da sífilis utilizado por Fleck nos mostra como um fato científico surge e é legitimado, e esclarece que "à medida que os estilos de pensamento são alterados ao longo da história, o próprio fato científico também assume esse caráter de transformação, acomodação e desenvolvimento, adaptando-se em cada período ao estilo dominante." (PARREIRAS, 2006, p. 59).

As comunidades de fala nada mais são do que a manifestação de um estilo de pensamento que é intensificado pelo constante entrecruzamento de ideias. Se passamos a compreender o modo com que uma ciência como a linguística constrói conhecimento partindo dessa perspectiva, que leva em conta as trocas e os pontos de encontro entre as mais diversas teorias linguísticas, o desenho do que temos é muito mais complexo e embaralhado do que a ideia de intradutibilidade faz crer.

\section{O PARADIGMA CIENTÍFICO E O PARADIGMA HUMANISTA}

Não há dúvidas de que há formas de investigação diferentes na linguística contemporânea e uma dificuldade em delimitá-las é precisamente o fato de que elas são permeáveis e há muitas miscigenações. Nesse sentido, não é uma tarefa simples apresentar um desenho do panorama atual das diferentes maneiras de se fazer linguística. Afinal, qual seria a melhor forma de organizar as teorias de modo a delinearmos o atual quadro das pesquisas em linguística? Que critérios utilizar?

A presente seção tem como objetivo discutir a proposta de descrição que organiza os estudos linguísticos em dois grandes "paradigmas", um termo que Pires de Oliveira e Basso (2011) utilizam frouxamente, sem referência direta à epistemologia kuhniana. Para os autores, podemos entender os estudos atuais em 
linguística centrados em duas metodologias de abordagem do objeto teórico: o paradigma científico e o paradigma humanista.

No paradigma científico, as teorias linguísticas são separadas em dois programas de pesquisa, de um lado os estudos formalistas que propõem uma descrição lógico-formal da língua, e de outro, os estudos funcionalistas que fazem previsões probabilísticas em suas análises. De um lado, o pensamento formalista se volta para a forma linguística, ou melhor, para a estrutura da linguagem, e de outro, o pensamento funcionalista está voltado para a função e o uso da linguagem (PIRES DE OLIVEIRA, BASSO, 2011).

Para Pires de Oliveira e Basso (2011), essas duas abordagens enquadram-se na definição de ciência e de prática científica como aquela que "(...) tem por objetivo a explicação de fenômenos teoricamente relevantes (...), a partir da construção de hipóteses indutivas ou dedutivas sobre fenômenos, que os explicam" (PIRES DE OLIVEIRA, BASSO, 2011, p. 35) e que são passíveis de serem refutadas. As teorias que não se constroem como passíveis de refutação não são consideradas "científicas", e, portanto não entram no paradigma científico. Mas os autores tomam muito cuidado para mostrar que ser científico não é mais ou menos positivo; trata-se simplesmente da adoção de uma metodologia de pesquisa.

O paradigma científico reuniria as teorias linguísticas comprometidas com o método científico, que se define por uma descrição dos fenômenos utilizando uma linguagem clara, arregimentada, a formulação de hipóteses que podem ser verificadas experimentalmente e, portanto, abandonadas ou refutadas. Nessa abordagem, uma teoria é formal se ela possui uma metalinguagem arregimentada para expressar as suas hipóteses, como é o caso da física que utiliza a matemática (cf. PIRES DE OLIVEIRA, 2004). Abordagens científicas se comprometem eticamente com uma descrição que é ao máximo isenta do cientista, isto é objetiva e pública. O cientista tem por obrigação explicitar o mais claramente possível a sua teoria para que outros possam realizar sua verificação (e possível refutação). Assim, tanto formalistas quanto funcionalistas adotariam esse compromisso.

Por outro lado, o paradigma humanista em linguística abrigaria áreas de estudo como as teorias enunciativas e a análise do discurso, para as quais o próprio conceito de refutação faz pouco sentido ${ }^{5}$. 0 ponto de partida para esses estudos se dá de outra perspectiva. Trata-se de uma perspectiva que leva em conta principalmente o sujeito da fala e o discurso como um acontecimento; por isso sua metodologia é qualitativa. A análise do discurso, por exemplo, apresenta um programa de estudos pensando a linguagem enquanto fato social único e elegendo o discurso, enquanto ato único, como seu objeto teórico (cf. MAZIÈRE, 2005, FERNANDES, 2008).

Para Orlandi (1994), "[a] Análise de Discurso se constitui no espaço disciplinar que põe em relação a Linguística com as Ciências Sociais." (ORLANDI, 1994, p. 52). Esta é uma proposta de análise linguística que tem como um dos seus principais objetivos apontar para o sujeito da fala e para a relação estabelecida entre esse sujeito e sua exterioridade, especificamente a relação entre o sujeito e os discursos. A aproximação da análise do discurso com as ciências sociais não se dá apenas como forma de complementação de uma pela outra, ao contrário, essa aproximação pretende gerar um ponto de tensão entre esses dois saberes. Vejamos o que diz Orlandi (1994, p. 53) a respeito da análise do discurso enquanto disciplina de entremeio: 
Em suma, a Linguística exclui a exterioridade, e as Ciências Sociais tratam a linguagem como se ela fosse transparente. A Análise de Discurso, por seu lado, ao levar em conta tanto a ordem própria da linguagem como o sujeito e a situação, não vai simplesmente juntar o que está necessariamente separado nessas diferentes ordens de conhecimento. Ao contrário, ela vai trabalhar essa separação necessária, isto é, ela vai estabelecer sua prática na relação de contradição entre esses diferentes saberes. Desse modo, ela não é apenas aplicação da Linguística sobre as Ciências Sociais ou vice-versa. A Análise de Discurso produz realmente outra forma de conhecimento, com seu objeto próprio, que é o discurso. Este, por sua vez, se apresenta como o lugar específico em que podemos observar a relação entre linguagem e ideologia. (ORLANDI, 1994, p. 53).

A posição de onde fala a autora é de controvérsia, como não poderia deixar de ser, já que ela pretende fundar uma nova teoria.

Portanto, para os analistas do discurso, importa confrontar a linguagem e tudo aquilo que está fora da linguagem, mais especificamente, os aspectos ideológicos entremeados à linguagem. Nessa abordagem, o sentido não está fixado aprioristicamente, ao contrário, há uma determinação histórica do sentido que deve ser levada em conta a cada interpretação de um fenômeno linguístico. Estamos nos remetendo ao sujeito e principalmente a noção de que o mundo do sujeito é um mundo constituído pela ideologia, que "é vista como o imaginário que medeia a relação do sujeito com suas condições de existência." (ORLANDI, 1994, p. 56). Por fim, "no discurso, o mundo é apreendido, trabalhado pela linguagem e cabe ao analista procurar apreender a construção discursiva dos referentes. A ideologia é, pois, constitutiva da relação do mundo com a linguagem, ou melhor, ela é condição para essa relação" (ORLANDI, 1994, p. 56).

Embora o funcionalismo também remeta à dimensão social e histórica do sujeito, seu procedimento de análise e sua metodologia difere daquela utilizada pelas abordagens humanistas. Para Pires de Oliveira e Basso (2011), no paradigma humanista,

[...] não há construção de um modelo abstrato que visa explicar universalmente os fenômenos de interesse, não há generalização nem previsão, tampouco parece haver refutação ou experimentos cruciais. Isso ocorre porque, nesse modo de reflexão, interessa a particularidade, o caso irreproduzível, a singularidade" (PIRES DE OLIVEIRA, BASSO, 2011, p. 37).

Diferentemente da prática científica, que constrói teorias verificáveis e refutáveis, trabalha-se com a particularidade de um evento ou fenômeno, o seu acontecimento.

É exatamente por essa razão que, na análise do discurso, a subjetividade torna-se o foco da sua reflexão: o sujeito da enunciação única e irreproduzível. Se estamos lidando com o particular, estamos lidando com o imprevisível, com aquilo que nem mesmo as teorias de probabilidade podem explicar. $O$ tipo de fenômeno que interessa a vertente humanista não pode ser explicado através de cadeias causais, como aquelas que aplicamos aos objetos naturais; esses fenômenos precisam de uma explicação de outra ordem, que leve em conta ponderações sobre a história, a ideologia, a psique do sujeito entre outros fatores. (PIRES DE OLIVEIRA, BASSO, 2011, p. 37).

O critério de validação dessas explicações está na "discutibilidade" de uma interpretação, pois, "se não é possível refutar as interpretações, as humanidades precisam de outro critério para validar suas explicações e esse critério parece ser 
a "discutibilidade", sua capacidade de engendrar interpretações." (PIRES DE OLIVEIRA, BASSO, 2011, p. 39). Caso não haja mais discussão em torno de uma interpretação considera-se, então, que esta não é mais uma teoria esclarecedora o bastante. A teoria se esgota quando a interpretação não é mais original e não mais ilumina os fenômenos de interesse (cf. SAHLINS, 2004).

Como vemos, o critério básico para a separação dos estudos linguísticos está na utilização de diferentes tipos de metodologia. Com base nisso, teríamos, na linguística, dois modelos gerais de reflexão, de um lado o paradigma científico e de outro o paradigma humanista. Vejamos abaixo o quadro geral com a proposta de distribuição dos paradigmas, conforme proposto por Pires de Oliveira e Basso (2011, p. 81):

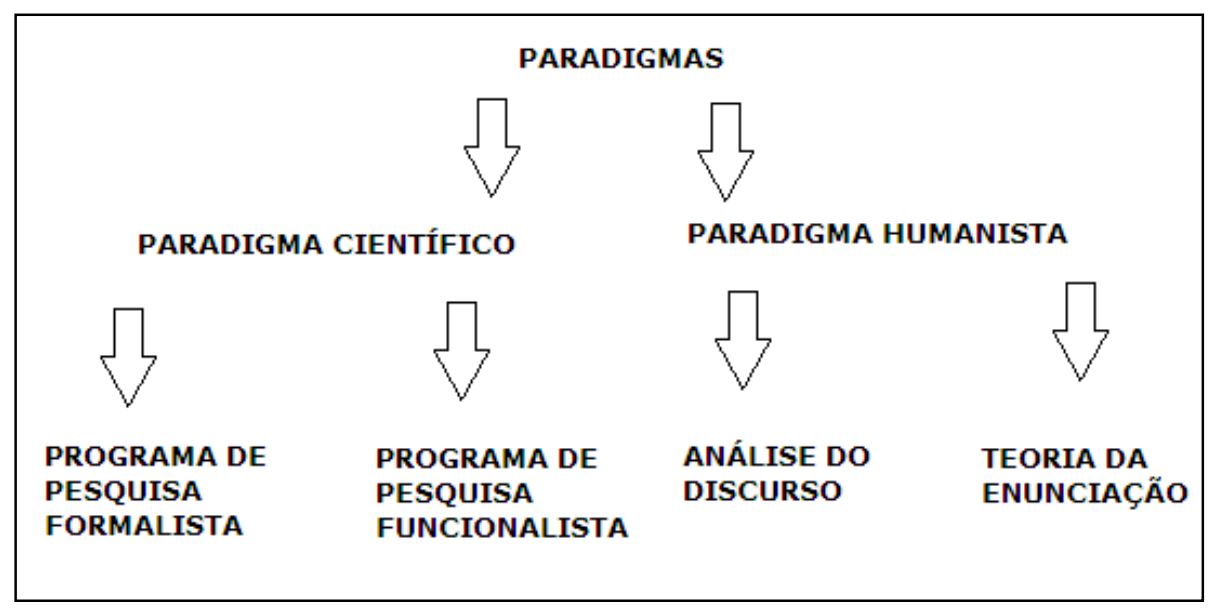

Figura 1: proposta epistemológica de distribuição dos paradigmas de abordagem do objeto linguagem.

O quadro separa os estudos linguísticos em dois paradigmas, sendo que “(...) os paradigmas devem ser encarados como um conjunto de métodos, de perguntas e de respostas possíveis." (BASSO, PIRES DE OLIVEIRA, 2011, p. 81).

\section{CRÍTICAS À PROPOSTA DE PARADIGMAS NA LINGUÍSTICA}

Pires de Oliveira e Basso (2011) deixam claro que utilizam o termo paradigma de uma maneira frouxa, porém, mesmo assim, podemos questionar se seria possível aplicar as noções de revolução científica e de ciência normal na linguística. Como veremos, adotar essa perspectiva irá nos levar à ideia de incomensurabilidade.

Como vimos anteriormente, a proposta lança mão de uma generalização que pretende basicamente estabelecer a separação entre duas formas distintas de reflexão nos estudos linguísticos contemporâneos. Pires de Oliveira e Basso (2011) afirmam que mundo, mas que esses modos são incomensuráveis e, portanto, intraduzíveis. Por exemplo, a palavra 'força', na teoria aristotélica de movimento, não tem o mesmo significado que essa palavra tem na teoria da relatividade e não há como traduzir enunciados de uma teoria na outra. Se não podemos traduzir, não podemos avaliar qual é a melhor teoria. Como veremos, em alguma medida, é esse de fato o caso, as diferentes práticas em que os linguistas se 
encontram não entendem 'linguagem' da mesma forma. Com esse cuidado suponhamos então que seja possível distinguir dois paradigmas na linguística contemporânea: o científico e o humanista. (BASSO, PIRES DE OLIVEIRA, 2011, p. 23, grifo nosso).

Nesse sentido, a proposta de paradigmas contribui para a visão de que as teorias são intraduzíveis, compartilhando com a compreensão de que

\begin{abstract}
(p)rovavelmente o caminho do linguista diverge do caminho do físico, nesse momento: enquanto o físico procura unificar sua ciência, buscando uma teoria que unifique a física quântica (que trata bem do microcosmos) e a física relativística (que trata bem do macrocosmos), caberia ao linguista estabelecer que porções de seu objeto constituiriam áreas "intradutíveis". (BORGES NETO, 2010, p. 3).
\end{abstract}

A reflexão de Pires de Oliveira e Basso (2011) não assume, no entanto, que há intradutibilidade entre as teorias, o que é uma decorrência da proposta de paradigmas; antes, ela parece se aproximar do modo como Fleck (1979) descreve o desenvolvimento de um conceito científico como o de sífilis, enquanto decorrência de convergências de várias linhas de pensamento que se entrecruzam para produzirem o conhecimento. Assim, diferentemente da visão "arrumada" em caixinhas de autores como Borges Neto e Dascal (1991), entre outros, para quem cada teoria é única, Pires de Oliveira e Basso (2011) parecem entender que as teorias são fluxos de conversas que se cruzam. Há sempre a possibilidade de conversa e de formação de novas conversas, daí pensarmos os modelos de reflexão em linguística como comunidades de fala, ressaltando assim a ideia de que a construção do conhecimento se faz através de constante diálogo e trocas teóricas.

Mas ao adotarem o conceito de paradigma, os autores retornam a ideia de incomensurabilidade. Como já dissemos, esse conceito filia-se à reflexão de Thomas Kuhn (1982) que propõe a existência de rupturas teóricas na ciência, chamadas de revoluções científicas. Essas rupturas modificariam radicalmente a visão de mundo assumida pelos cientistas, instaurando uma maneira totalmente nova de perceber o objeto de estudo. Um paradigma pode ser entendido como "um campo ou 'mundo' conceitual, que representa uma maneira de investigar uma série de fenômenos acoplada a uma visão de mundo e que constitui a chamada ciência normal, momentos em que a comunidade científica está em consenso". (PIRES DE OLIVEIRA, BASSO, 2011, p. 20).

O período de ciência normal começa a ser abalado quando se observam anomalias dentro do paradigma vigente. A partir daí começa a se desenrolar uma série de discussões, passando-se para um período de ciência extraordinária. Segundo Kuhn (1982, p.115-116), podemos ter três diferentes desfechos dessa situação: i) o paradigma vigente consegue explicar as anomalias e assim a crise é contornada; ii) os cientistas deixam de lado as anomalias para serem resolvidas no futuro; ou ii) o paradigma é substituído por um novo, que consegue resolver as anomalias geradoras da crise. Neste último caso, temos o que Kuhn chama de revolução científica propriamente.

Com o novo paradigma devidamente estabelecido, inicia-se novamente um período de ciência normal. Um dos pontos dessa teoria sobre o desenvolvimento do conhecimento científico é perceber que a ciência deixa de ser apenas um empreendimento cumulativo para ser historicamente demarcada por uma 
sucessão de revoluções nas quais padrões de pensamento ou de métodos se modificam radicalmente abrindo assim o campo para um novo despertar de ideias e de novos jogos possíveis; o que certamente é um avanço tendo em vista a visão mais romântica de ciência como produção cumulativa de conhecimento.

A proposta de Kuhn pretende explicar a passagem do modelo aristotélico na física para o modelo newtoniano. Em A estrutura das revoluções científicas, umas de suas obras mais influentes, Kuhn afirma que

[...] "ciência normal" significa a pesquisa firmemente baseada em uma ou mais realizações científicas passadas. Essas realizações são reconhecidas durante algum tempo por alguma comunidade científica específica como proporcionando os fundamentos para sua prática posterior. Embora raramente na sua forma original, hoje em dia essas realizações são relatadas pelos manuais científicos elementares e avançados. Tais livros expõem o corpo da teoria aceita, ilustram muitas (ou todas) as suas aplicações com observações cedidas e comparam essas aplicações com observações e experiências exemplares. (KUHN, 1982, p. 29).

Entendendo por paradigma aquilo que se refere ao campo conceitual que instaura uma forma de investigar e até mesmo de perceber os fenômenos, fundamentado por meio de manuais, o primeiro passo para utilizar o termo paradigma é verificar se a linguística está numa fase de ciência normal ou se já esteve em tal fase. Se de fato a linguística pode ser dividia em paradigmas, poderíamos questionar se estamos vivendo um momento de ciência extraordinária ou de ciência normal. Na citação abaixo, vemos o que Kuhn diz a respeito dos momentos de crise na ciência.

\begin{abstract}
A transição de um paradigma em crise para um novo, do qual pode surgir uma nova tradição de ciência normal, está longe de ser um processo cumulativo obtido através de uma articulação do velho paradigma. É antes uma reconstrução da área de estudos a partir de novos princípios, reconstrução que altera algumas das generalizações teóricas mais elementares do paradigma, bem como muitos de seus métodos e aplicações. Durante o período de transição haverá uma grande coincidência (embora nunca completa) entre os problemas que podem ser resolvidos pelo antigo paradigma e os que podem ser resolvidos pelo novo. Haverá igualmente uma diferença decisiva no tocante aos modos de solucionar os problemas. Completada a transição, os cientistas terão modificado a sua concepção da área de estudos, de seus métodos e de seus objetivos. (KUHN, 1982, p. 116).
\end{abstract}

Um estudo epistemológico da linguística, que utilize a metodologia de Kuhn, deve procurar responder como e quais seriam as revoluções científicas que deram início a um período de 'ciência normal'. No caso particular da linguística, deveríamos saber o que deu início aos paradigmas, e com base nas respostas a essas questões poderíamos avaliar se a linguística está passando por um momento de transição de paradigmas ou não. Na proposta de Pires de Oliveira e Basso (2011) não há esse tipo de discussão e nem se coloca em pauta algumas dessas noções associadas ao conceito de paradigma utilizado.

Portanto, pensar a linguística em termos kuhnianos exige primeiramente a análise dos momentos de revolução científica, e também nesse ponto parece haver certas particularidades que tornam não muito óbvias o enquadramento das 
revoluções ocorridas na linguística naquilo que seria uma revolução kuhniana. (cf. BORGES NETO, 1990).

Vejamos o que Borges Neto constata sobre a possibilidade de aplicar a metodologia kuhniana para analisar o embate entre o Estruturalismo Americano e a Gramática Gerativa.

Mesmo tendo como referência apenas a breve e esquemática apresentação das ideias de Kuhn que fizemos acima podemos perceber que não é muito difícil caracterizar o EA (Estruturalismo Americano) e a GGT (Gramática Gerativa Transformacional) como dois paradigmas distintos: os pressupostos metafísicos não são os mesmos; as exigências feitas aos trabalhos de pesquisa são distintas; a noção de problema linguístico bem resolvido não é a mesma; as generalizações simbólicas e os exemplos também são distintos. Por outro lado, as características gerais do surgimento e da expansão da GGT não tornam a "revolução chomskyana" um exemplo claro, transparente, de revolução científica. (BORGES NETO, 1990, p. 84, negrito e sublinhado do autor).

Apesar de a Gramática Gerativa apresentar vários indícios de ter sido de fato uma espécie de revolução científica na linguística, pois aparentemente apresenta uma abordagem totalmente nova sobre a linguagem, o autor descarta o uso do modelo kuhniano em sua análise ao observar que: i) não havia crise na linguística norte-americana em meados da década de 1950, época em que Chomsky publica Syntact Structures, considerada a obra que dá início a história da GGT; ii) Chomsky não propõe a GGT para ser um paradigma solucionador a uma possível crise do paradigma anterior, ao contrário, a GGT surge como uma espécie de complemento ao EA; iii) o EA não foi abandonado pela comunidade linguística, inclusive alguns trabalhos incorporaram aspectos da nova teoria; iv) apesar da postura que alguns adeptos da GGT mantiveram com relação ao EA, ao considerar a GGT revolucionária, seria insuficiente enquadrar a GGT como uma revolução científica no sentido kuhniano.

\footnotetext{
Diante da constatação de que o enquadramento da "revolução chomskiana" no conceito de revolução científica de Kuhn não é obvio, para dizer o menos, podemos pensar em alternativas. Uma alternativa é garantir o modelo de Kuhn, mas afirmar que ele não se aplica ao caso específico da linguística por causa de características próprias desta ciência. (...) Outra alternativa seria considerarmos que o modelo de Kuhn é adequado para o tratamento da história da linguística mas que as pessoas que tem tentado esse enquadramento não conseguiram achar o lugar correto da linguística no modelo. (BORGES NETO, 1990, p. 86-87).
}

Lahud (apud Borges Neto, 1990) defende que o modelo de Kuhn pode ser aplicado à linguística, desde que descartado o conceito de revolução científica. Nesse caso, teríamos antes a constatação de que a linguística permanece em um estado pré-paradigmático, isto é, não só não haveria paradigmas na linguística, como as revoluções científicas seriam impossíveis de acontecer, pois sequer estaríamos em uma fase paradigmática. Para Assis, autor que discute o uso do conceito kuhniano aplicado às ciências sociais,

(u)ma determinada atividade com pretensões ao conhecimento atinge a fase paradigmática quando para de haver debate em torno de princípios. As diversas escolas que estudam determinado conjunto de fenômenos 
partidárias de diferentes fundamentos, baseados em diferentes ontologias e que enfocam um mal definido conjunto de problemas, cada uma a sua maneira. A certa altura, uma das escolas começa a ganhar adeptos, o que sufoca as tradições rivais. (ASSIS, 1993, p. 136).

Com relação a um possível estado pré-paradigmático na linguística, Borges Neto (1990) endossa os argumentos de Lahud, dizendo que

\begin{abstract}
(n)ão é difícil arrolar alguns argumentos em favor da posição de Lahud. Em primeiro lugar, nunca houve, em toda a história da linguística, uma teoria que conseguisse - de forma clara e inconteste - a aceitação geral dos linguistas de uma certa geração. Em segundo lugar, é difícil pensar, por exemplo, no estruturalismo como um paradigma kuhniano, colocando "no mesmo saco" bloomfieldianos, sapirianos, glossemáticos, firthianos, etc. em terceiro lugar, se observarmos as várias histórias da linguística, veremos que a época do surgimento do "primeiro paradigma" muda constantemente, conforme a formação e o interesse do historiador. Para uns, o primeiro paradigma foi o da linguística histórico-comparativa; para outros ainda, é apenas com a GGT que a linguística adquire "uma estrutura lógica, científica" (Mitsou Ronat em Chomsky 1977, p.103), ou adquire "uma perspectiva verdadeiramente científica” (Neymeyer 1980, p. 20). (BORGES NETO, 1990, p. 88).
\end{abstract}

Nas palavras do próprio Kuhn (1982, p. 72-73),

(o) período pré-paradigmático, em particular, é regularmente marcado por debates frequentes e profundos a respeito de métodos, problemas e padrões de solução legítimos - embora esses debates sirvam mais para definir escolas do que para produzir um acordo.

Em vista das dificuldades apresentadas em aplicar o modelo de Kuhn para o caso da linguística, seria indicado outro modelo que ofereça uma saída mais apropriada para o tratamento das teorias linguísticas. Como já viemos apontando, a teoria epistemológica de Fleck oferece uma outra forma de abordarmos a epistemologia da linguística que é mais apropriada ao modo como essa ciência produz conhecimento. $O$ conceito de paradigma, por levar necessariamente a ideia de incomensurabilidade, não traduz o que observamos de fato; as teorias linguísticas estão muito mais estabelecendo conversas entre si do que cada uma fechada em sua própria linguagem sem levar em conta o que as outras teorias estão construindo. Antes parece que há fluxos de conversas que se cruzam. Portanto, a teoria fleckiana parece ser a mais indicada para que haja um estudo epistemológico dessa ciência, especificamente com relação ao conceito de comunidades de fala.

\title{
CONCLUSÃO
}

O presente artigo abordou uma proposta de divisão dos estudos linguísticos contemporâneos que toma por critério as metodologias utilizadas pelas teorias linguísticas contemporâneas. Pires de Oliveira e Basso (2011) propõem dois "paradigmas" distintos, ou seja, duas formas distintas de refletir sobre os fenômenos linguísticos, levando em conta a metodologia aplicada nas mais diversas áreas da linguística.

De um lado, temos pesquisas em linguística realizadas com base em métodos científicos, as pesquisas formalistas e funcionalistas. Por outro lado, a linguística também abriga estudos que são realizados com base em uma metodologia do 
acontecimento, como é o caso da análise do discurso e das teorias da enunciação. Assim como na história, os estudos dentro desse paradigma se debruçam sobre eventos particulares, e buscam propor interpretações sobre fenômenos que são irreprodutíveis.

Nosso objetivo foi mostrar que o uso do conceito de paradigma pelos autores é inadequado por basicamente dois motivos: (i) contrariamente ao que afirmam autores como Borges Neto e Dascal (1991), as teorias na linguística não são intradutíveis, uma exigência da ideia de paradigmas que são incomensuráveis; (ii) a ideia de que a linguística passou por um período de ciência normal e por revoluções científicas parece questionável mesmo para a emergência da Gramática Gerativa. Sugerimos que uma maneira mais adequada para entendermos a linguística é um modelo como o de Fleck em que as várias comunidades que constituem linhas de pensamento estão em interação. Indicamos que a ideia de teorias intradutívies não encontra respaldo empírico, como mostra a sociolinguística paramétrica e o estudo sobre o foco.

Sem sombra de dúvidas, esse artigo antes evidencia a necessidade de mais debates em epistemologia da linguística e uma necessária discussão quanto à constituição dessa ciência do que apresenta soluções. 


\title{
The science of language: a reflection about the concept of paradigm
}

\begin{abstract}
This paper critically discusses Pires de Oliveira and Basso (2011) epistemological claim that there would be two paradigms in contemporary linguistics: the scientific and the humanistic ones. The aim of this paper is to reflect on the validity of the concept of paradigm in case of linguistics, since it is not clear that the concept applies to this science. We shall argue that contemporary linguistics is better described through the concept of speech communities. Thus, it is expected to motivate new studies on the necessary discussion in epistemology of linguistics, especially as regards the application of Kuhn's model.
\end{abstract}

KEYWORDS: Scientific paradigm. Humanistic paradigm. Epistemology of linguistics. Speech community. 


\section{NOTAS}

1 Há tanto autores que acreditam que a gramática gerativa constitui uma revolução no sentido kuhniano, quanto autores que afirmam não haver, até o momento, nenhuma revolução na linguística nos termos de Kuhn. Podemos citar Searle (1972) para uma defesa de que houve uma revolução no sentido kuhniano e Koerner (manuscrito) para uma problematização dessa afirmação.

2 Basta uma breve revisão de um problema linguístico para ver que não é esse o caso; não apenas as teorias conversam, mas essa conversa faz alterações nas teorias e avança a compreensão. Considere, por exemplo, o problema do foco que teve início com a reflexão funcionalista, foi para o gerativismo e hoje há consensos compartilhados tanto por uns quanto por outros. Parece assim não haver uma delimitação rígida, estabelecida e intransponível entre diferentes teorias, as trocas podem ocorrer em parte porque o objeto não é tão distinto quanto querem fazer crer os que gostariam que cada teoria ficasse restrita em seus próprios limites.

3 Ver Chierchia (2013) para um exemplo radical dessa pesquisa na interface, por exemplo.

4 Para os autores que propõem a sociolinguística paramétrica "empreenderemos, sim, um novo caminho: aquele que resgata a compatibilidade entre as propriedades paramétricas do modelo gerativo e as probabilidades do modelo variacionista, seja para provar seu espelhamento e reflexo, seja para realinhar um modelo em função do outro. Acreditamos, assim, num direcionamento mútuo entre a variação intra- e inter-linguística, enfim: na harmonia trans-sistêmica." (TARALLO, KATO, 1989, p. 16).

5 Em Pires de Oliveira e Basso (2011) aborda-se com mais detalhes a Análise do Discurso, as teorias enunciativas são somente citadas como pertencentes ao paradigma humanista sem que haja uma discussão sobre suas características e procedimentos de análise.

\section{REFERÊNCIAS}

BORGES NETO, José. A gramática gerativa transformacional: Um ensaio de Filosofia da Linguística. 1990. 277 f. Tese (Doutorado) - Curso de Pós-graduação em Linguística do Instituto de Estudos da Linguagem, Universidade Estadual de Campinas, Campinas, 1990.

História e Filosofia da Linguística: uma entrevista com José Borges Neto. ReVEL. Vol. 8, n. 14, 2010.

O pluralismo teórico na Linguística. Estudos Linguísticos (São Paulo), v. 25, p. 1-14, 1996.

BORGES NETO, José; DASCAL, Marcelo. De que trata a linguística, afinal? In: Histoire Épistémologie Langage. Tome 13, fascicule 1, 1991. pp. 13-50. 
CHIERCHIA, Gennaro. Logic in Grammar: Polarity, Free Choice and Intervention. Oxford: Oxford University Press, 2013.

CHOMSKY, Noam. Syntactic Structures. The Hague: Mouton, 1957.

FERNANDES, Cleudemar Alves. Análise do discurso: reflexões introdutórias. São Carlos: Editora Claraluz, 2008.

FLECK, Ludwik. The Genesis and Development of a Scientific Fact. Chicago: The University Of Chicago Press, 1979.

KUHN, Thomas. A estrutura das revoluções científicas. Traduzido por Beatriz Vianna Boeira e Nelson Boeira. São Paulo: Editora Perspectiva, 1982.

KOERNER, Konrad. Linguistics and Revolution with particular reference to the 'Chomskyan Revolution'. Disponível em:

<http://uahost.uantwerpen.be/apil/apil106/EFKKoerner.pdf>. Acesso em: 01 out. 2015.

MAZIÈRE, Francie. A análise do discurso: história e processo. São Paulo: Editora Parábola, 2005.

ORLANDI, Eni. Discurso, imaginário social e conhecimento. Em Aberto, Brasília, n. 61, p.53-59, jan. 1994. Disponível em:

<http://www.emaberto.inep.gov.br/index.php/emaberto/article/viewFile/911/8 17>. Acesso em: 20 fev. 2015.

PARREIRAS, Márcia Maria Martins. Ludwik Fleck a historiografia da ciência: diagnóstico de um estilo de pensamento segundo as Ciências da Vida. 2006. 204 f. Dissertação (Mestrado) - Curso de Pós-graduação em História, Faculdade de Filosofia e Ciências Humanas da UFMG, Universidade Federal de Minas Gerais, Belo Horizonte, 2006. Disponível em:

<http://www.bibliotecadigital.ufmg.br/dspace/handle/1843/VCSA-6XTGF7>. Acesso em: 02 jan. 2016.

PIRES DE OLIVEIRA, Roberta. Formalismos na linguística: uma reflexão crítica. In: MUSSALIM, Fernanda; BENTES, Ana Cristina. Introdução à linguística: fundamentos epistemológicos. São Paulo: Cortez Editora, 2004. p.219-250.

PIRES DE OLIVEIRA, Roberta; BASSO, Renato. Filosofia da Linguística. 
SAHLINS, Marshall David. Esperando Foucault, ainda. São Paulo: Cosac \& Naify, 2004.

SAUSSURE, Ferdinand. Curso de linguística geral. Traduzido por Antônio Chelini, José Paulo Paes e Izidoro Blikstein. São Paulo: Cultrix, 1995.

SEARLE, John R.. A Special Supplement: Chomsky's Revolution in Linguistics. 1972. Disponível em: <http://www.nybooks.com/articles/1972/06/29/a-specialsupplement-chomskys-revolution-in-lingui/>. Acesso em: 05 jan. 2016.

TARALLO, Fernando; KATO, Mary. Harmonia Trans-sistêmica: Variação Intra e Inter-Linguística. Preed. 5. Campinas: Unicamp, 1989. 
Recebido: 17 abr. 2015

Aprovado: 7 abr. 2016

DOI: $10.3895 /$ rl.v18n22.3239

Como citar: DAMÁZIO, P.R.S.D; OLIVEIRA, R.P. Ciência da Linguagem: uma reflexão sobre o conceito de paradigmas. R. Letras, Curitiba, v. 12, n. 24, p. 1-10, jan./jul. 2016. Disponível em:

<https://periodicos.utfpr.edu.br/rl>. Acesso em: XXX.

Direito autoral: Este artigo está licenciado sob os termos da Licença Creative Commons-Atribuição 4.0 Internacional. 